Article

\title{
The Influence of Warm Rolling Reduction on Microstructure Evolution, Tensile Deformation Mechanism and Mechanical Properties of an Fe-30Mn-4Si-2Al TRIP/TWIP Steel
}

\author{
Yanchun Dong ${ }^{1,2}$, Zhilin Sun ${ }^{1}$, Hao Xia ${ }^{1}$, Jianhang Feng ${ }^{1,2}$, Jiejie Du ${ }^{1}$, Wei Fang ${ }^{1,2}$, \\ Baoxi Liu ${ }^{1,2}$, Gongkai Wang ${ }^{1,2}$, Long $\mathrm{Li}^{3}$, Xin Zhang ${ }^{1,2, *}$ and Fuxing Yin 1,2,* \\ 1 Research Institute for Energy Equipment Materials, School of Materials Science and Engineering, \\ Hebei University of Technology, Tianjin 300130, China; hbgddych@163.com (Y.D.); \\ sunzhilinhebut@163.com (Z.S.); hao_xia@foxmail.com (H.X.); 13933765819@126.com (J.F.); \\ dujiejie158@163.com (J.D.); fangwei@hebut.edu.cn (W.F.); liubaoxiliubo@126.com; (B.L.); \\ wang.gongkai@hebut.edu.cn (G.W.) \\ 2 Tianjin Key Laboratory of Materials Laminating Fabrication and Interface Control Technology, \\ Hebei University of Technology, Tianjin 300130, China \\ 3 Yinbang Clad Material Co., Ltd., Wuxi 214145, China; lichen040928@163.com \\ * Correspondence: zhang_xin@hebut.edu.cn (X.Z.); yinfuxing@hebut.edu.cn (F.Y.)
}

Received: 5 September 2018; Accepted: 19 September 2018; Published: 21 September 2018

\begin{abstract}
The effects of warm rolling reduction ratio ranging from $20 \%$ to $55 \%$ on microstructure evolution, the tensile deformation mechanism, and the associated mechanical properties of an Fe-30Mn-4Si-2Al TRIP/TWIP steel were studied. The warm rolling process resulted in the formation and proliferation of sub-structure, comprising dislocations, deformation twins as well as shear bands, and the densities of dislocation and twins were raised along with the increase in rolling reduction. The investigated steel, with a fully recrystallized state, exhibited a single $\varepsilon$-TRIP effect during the room temperature tensile deformation, on top of dislocation glide. However, the formation and growth of twin lamellae and $\varepsilon$-martensite were detected simultaneously during tensile deformation of the warm rolled specimen with rolling reduction of $35 \%$, leading to a good balance between high yield strength of $785 \mathrm{MPa}$, good total ductility of $44 \%$, and high work hardening rate. As the rolling reduction increased to $55 \%$, the specimen revealed a relatively low work hardening rate, due to the high dislocation density, and dislocation glide was the main deformation mechanism. As a result, a tensile deformation mechanism that started from a single $\varepsilon$-martensitic transformation moved to a bi-mode of $\varepsilon$-martensitic transformation accompanied with deformation twinning, and finally to dislocation glide with the increasing warm rolling reduction was proposed.
\end{abstract}

Keywords: TRIP/TWIP steel; warm rolling; martensitic transformation; deformation twin; yield strength; tensile deformation behavior

\section{Introduction}

TRIP/TWIP steel with high strength-elongation product and high energy absorption capability offers a promising perspective for the automotive industry, since the attractive mechanical properties derive from the formation of $\varepsilon / \alpha^{\prime}$ martensite (TRIP effect, Transformation Induced Plasticity), or deformation twins (TWIP effect, Twinning Induced Plasticity) [1-6]. The occurrence of a TRIP and/or TWIP effect depends on the stacking fault energy (SFE) of the austenitic matrix, which is mainly governed by alloy content and deformation temperature [7]. It has been reported that deformation 
induced martensite transformation usually happens on steels with low SFE, whereas twinning occurs with elevated SFE [8].

However, a relatively low yield strength of TRIP/TWIP steel (approximately 200 to $400 \mathrm{MPa}$ ) has limited further industrial development, particularly with respect to crash-relevant parts [9]. Great efforts have been directed towards improving the yield strength of TRIP/TWIP steel [10-12]. Herein, strengthening by grain size refinement is shown to be an effective technique according to the Hall-Petch relationship [13]. The minimum grain size of around $2.5 \mu \mathrm{m}$ was the limitation that could be achieved by conventional cold rolling and annealing treatments, by which the yield strength only could be improved to $450 \mathrm{MPa}$ [9]. Severe plastic deformation, such as Equal Channel Angular Pressing (ECAP), could dramatically decrease the grain size to nano-scale [14]. However, it was still hindered by technological limitations regarding large-scale applications. Other methods, such as precipitation strengthening and pre-straining by cold rolling also improved the yield strength at the expense of ductility and work hardening rate $[1,10,15,16]$.

In order to circumvent this intractable issue, a novel approach of temperature dependence of deformation mechanisms in TRIP/TWIP steel was proposed in our previous study [17]. The strategy is to introduce the deformation twin by controlling the pre-strain temperature. Based upon that, asynchronous synergy of pre-strain twinning and $\varepsilon$-martensite transformation took effect, resulting in improved performance of TRIP/TWIP steels dominated by bimodal microstructures. The results demonstrated that the deformation mechanism could change from $\varepsilon$-martensitic transformation to deformation twinning, then dislocation glide with an increase in rolling temperature. It is worth noting that a large amount of deformation twins was formed after rolling at $673 \mathrm{~K}$, indicating the asynchronous synergy of pre-strain twinning and $\varepsilon$-martensite transformation could be effectively developed by warm rolling at $673 \mathrm{~K}$. Therefore, further optimization of the deformation microstructure after warm rolling is crucially necessary.

In the present study, the influence of warm rolling reductions on the microstructure evolution, tensile deformation mechanism, and mechanical properties was analyzed. Particular focus was placed on the evolution of deformation twins and $\varepsilon$-martensite during the warm rolling process and subsequent plastic deformation at room temperature.

\section{Experimental Procedures}

\subsection{Material and Processing}

We selected a Fe-30Mn-4Si-2Al (wt. \%) alloy for this purpose, which shows the single $\varepsilon$-TRIP effect at room temperature and mechanical $\gamma$-twinning when deformation temperature is elevated. A $50 \mathrm{~kg}$ ingot of Fe-30Mn-4Si-2Al alloy (wt. \%) was produced by vaccum induction melting, followed by hot forging and hot rolling at $1473 \mathrm{~K}$ into a plate with the thickness of $5 \mathrm{~mm}$. The exact chemical composition of the alloy is shown in Table 1 . The homogenization heat treatment was performed at $1273 \mathrm{~K}$ for $1 \mathrm{~h}$ in a muffle furnace, followed by quenching in water in order to reduce segregation of the alloying elements. Subsequently, the as-annealed plates were warm rolled at $673 \mathrm{~K}$ to a $20 \%-55 \%$ reduction in thickness in several passes, using a laboratory scale rolling mill (here, the temperature range of warm rolling is $373-873 \mathrm{~K}$ for the experimental steel, considering the formation of a deformation twin [17]).

Table 1. Chemical composition of the experimental steels.

\begin{tabular}{ccccccc}
\hline Element & Mn & Si & Al & C & P & Fe \\
\hline (wt. $\%)$ & 29.99 & 4.06 & 1.98 & 0.004 & 0.002 & Bal. \\
\hline
\end{tabular}




\subsection{Microstructural Characterization}

Microstructure observations were analyzed using optical microscopy (OM, Zeiss company, Berlin, Germany), electron back scattering diffraction (EBSD, JEOL, Tokyo, Japan), and X-ray diffraction (XRD, Zeiss company, Berlin, Germany). The surface of the samples was sandpapered, polished, and etched in a 10\% nital solution. The EBSD measurement was conducted on a JEOL JSM-7100F field emission gun scanning electron microscope, equipped with a TSL orientation-imaging microscope (OIM) system. The step sizes used for the overview and details are $1 \mu \mathrm{m}$ and $0.07 \mu \mathrm{m}$, respectively.

Phase analysis was performed by means of XRD with $\mathrm{Cu} \mathrm{K} \alpha$ radiation. According to a Williamson-Hall plot, average values of crystallite size $d$ and microstrain $\left\langle\varepsilon_{50}^{2}\right\rangle$ were estimated. Then, dislocation density can be given by the following equation:

$$
\rho=\frac{3 \cdot(2 \pi)^{1 / 2}<\varepsilon_{50}^{2}>}{D b}
$$

where $b$ is the Burgers vector $\left(2.5 \times 10^{-10} \mathrm{~m}\right)$; $D$ is the average value of the crystallite size, which is determined according to the Sherrer formula.

The Vickers Hardness (HV) values of the specimens before and after warm rolling were tested using a $980 \mathrm{mN}$ load for $15 \mathrm{~s}$ dwelling time. Rectangular dog-bone shaped tensile specimens with gauge lengths of $25 \mathrm{~mm}$ and gauge width of $10 \mathrm{~mm}$ were machined from the as-annealed and as-rolled plates. The loading direction was parallel to the rolling direction (RD). Tensile tests were performed at an engineering strain rate of $6.7 \times 10^{-4} \mathrm{~s}^{-1}$, at room temperature.

\section{Results and Discussion}

\subsection{Microstructure Evolution}

The optical micrographs of the investigated steels with different warm rolling reductions are shown in Figure 1. The initial state of the as-annealed alloy is single face centered cubic (FCC) phase. The microstructure consists of globulitic grains with an average grain size of around $59 \mu \mathrm{m}$, as well as some annealing twins (Figure 1a). Figure 1b-d illustrate the microstructure evolution of TRIP/TWIP steel with different warm rolling reduction ratios of $20 \%, 35 \%$, and $55 \%$, respectively. At the lowest reduction (20\%), grains are slightly elongated along the RD, accompanied by a banded structure only in some favorably oriented grains (Figure 1b). Elongated grain structure is a common phenomenon during rolling deformation [18]. Kimura et al. reported that the mechanical properties are dramatically enhanced due to the ultrafine elongated grain structure processed by a thermomechanical treatment [18]. In specimens with rolling reductions of $35 \%$ and $55 \%$, the grains are further elongated and the banded structure can be observed in almost all of grains. The elevated rolling reduction significantly increases the density of the banded structure, in which slip bands, deformation twins, or $\varepsilon$-martensite may be included. In our previous results, the banded structures were confirmed as deformation twins after warm rolling at $673 \mathrm{~K}$ with a reduction of $20 \%$, although the steel in the fully recrystallized state exhibited the bare $\varepsilon$-TRIP effect after tensile deformation at room temperature [19]. This is because the SFE of the austenitic matrix is identified as the dominating factor that is mainly responsible for the deformation modes (deformation-induced martensitic transformation, dislocation slip, or twinning) in austenitic Fe-high Mn alloys. On the other hand, the temperature plays a key effect on the SFE, as the magnitude of SFE increases with temperature [20]. At a low deformation temperature $(298 \mathrm{~K})$, a low SFE results in deformation-induced martensitic transformation. At higher temperatures (373-673 K), an intermediate range of SFE leads to deformation twinning. As the temperature is further increased (873-1073 K), perfect dislocation glide with cross slip gradually replaces deformation twinning [17]. 

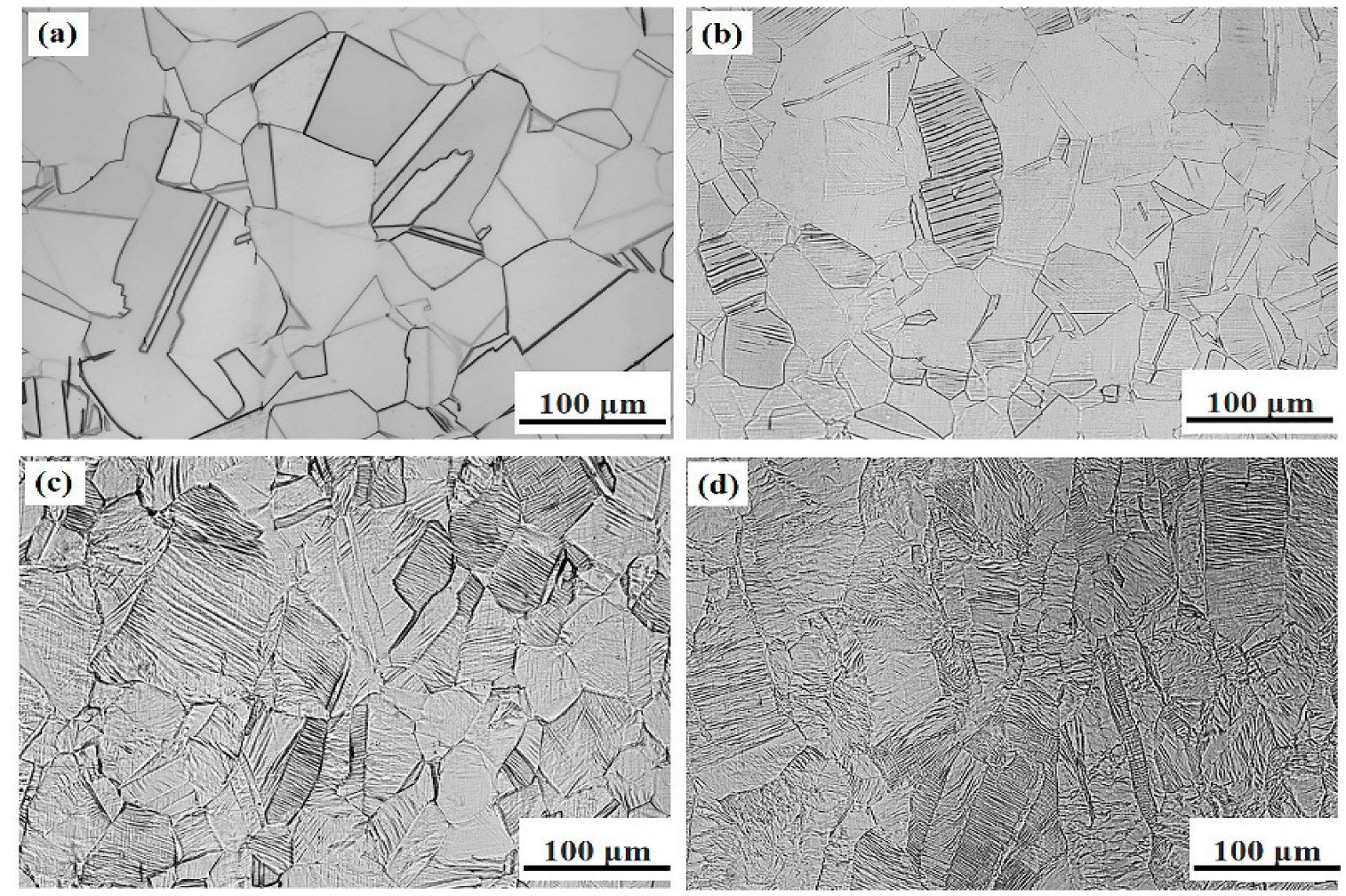

Figure 1. Optical micrographs showing the microstructure of specimens with different warm rolling reductions (a) $0 \%$, (b) $20 \%$, (c) $35 \%$, (d) $55 \%$.

XRD was performed to identify the deformation microstructure features. X-ray diffraction profiles of TRIP/TWIP steel with different rolling reductions are shown in Figure 2a. The XRD line diagrams of all experimental cases are found to be the single austenite phase, implying no occurrence of $\varepsilon$-martensite transformation with the increase in rolling reduction. Figure $2 b$ shows the effect of warm rolling reduction on dislocation density. The dislocation density is around $0.8 \times 10^{15} \mathrm{~m}^{-2}$ after warm rolling to a thickness reduction of $20 \%$. Then, the dislocation density gradually increases with strain and reaches a high value of $2.68 \times 10^{15} \mathrm{~m}^{-2}$ at $55 \%$ rolling reduction. The dislocation density is closely related to the deformation behavior of metallic materials. On the one hand, the strength of steels monotonically increases with dislocation density, based on the Taylor hardening law [21]. Therefore, dislocation is an effective pathway for strengthening, however, accompanied with the cost of ductility is the increase in dislocation density. Interestingly, He et al. recently suggested that the high dislocation density also enabled a large ductility by the glide of existing mobile dislocation during the deformed and partitioned (D\&P) process [22]. On the other hand, the density, characteristics, and distribution of dislocations exhibit a strong influence on SFE. A deformation-dependent SFE viewpoint is invoked to interpret the tensile deformation of a high Mn TWIP steel [23]. Pierce et al. indicated that effective SFE varied with the terms of density parameters and dislocation arrangement proportionally, besides alloy composition and deformation temperature [24]. Therefore, the effective SFE, which is the key parameter controlling the emergence of plasticity mechanisms, will increase with the increasing dislocation density. In other words, there is a close relationship between dislocation density and the plastic deformation mechanism. 
(a)

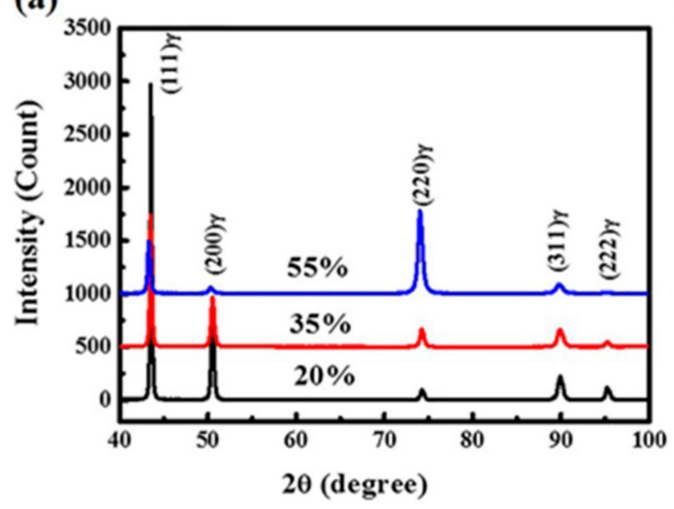

(b)

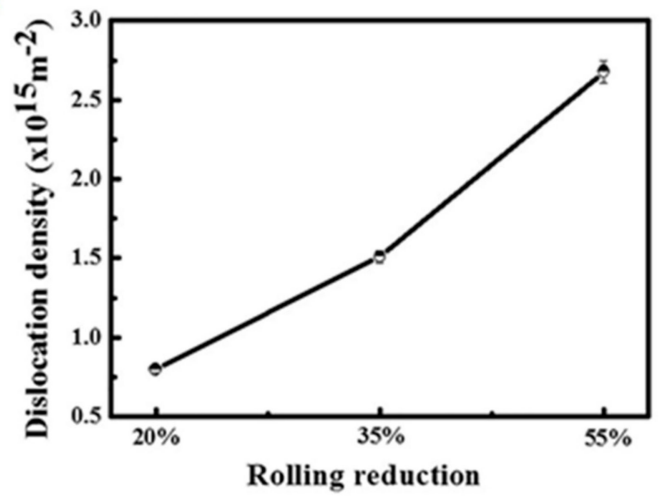

Figure 2. X-ray diffraction patterns of the specimens (a) and variation of dislocation density with increasing warm rolling degree $(\mathbf{b})$.

In order to further elucidate the microstructure evolution with the increasing rolling reduction, the EBSD results are shown in Figure 3. Figure $3 a_{1}$ showss typical recrystallized equiaxed grain structure with high fraction of annealing twins. The deformation grains are obviously elongated along the RD with increasing rolling reduction, consistent with the OM results, as shown in Figure $3 b_{1}, c_{1}, d_{1}$. At the $20 \%$ reduction state, the microstructure consists of small amounts of deformation twins (Figure $3 \mathrm{~b}_{1}$ ). After rolling to $35 \%$, a gradual increase in the deformation twin density occurs (Figure $3 c_{1}$ ). With further rolling to $55 \%$, formation of deformation twins can be observed in almost all of the grains. For analyzing the deformation microstructure in more detail, the corresponding enlarged images taken from the black framed areas in Figure $3 a_{1}, b_{1}, c_{1}, d_{1}$ are given, as shown in Figure $3 a_{2}, b_{2}, c_{2}, d_{2}$. At a reduction of $20 \%$, the microstructure consists of a small amount of deformation twins with a few tenths of micrometer wide in red color and some unidentified banded structure in dark color, as shown in Figure $3 b_{2}$. The unidentified banded structure may be very thin deformation twins which can not be detected by the resolution of EBSD, or slip bands. Furthermore, the high number of misorientation angles along the misorientation line profile further demonstrate the presence of twin bundles $\left(60^{\circ}\left\{\begin{array}{lll}1 & 1 & 1\end{array}\right\}\right)$, as shown in Figure $3 b_{3}$. At a rolling reduction of $35 \%$, the number of deformation twins increases dramatically, and the twin plates become clearly thicker (Figure $3 c_{2}, d_{2}$ ). When the rolling reduction reaches $55 \%$, the deformation microstructure becomes more complex. In addition to deformation twins and slip bands, another important feature is the appearance of shear bands. The shear band is a kind of highly strained bands inclined to the RD direction by $25^{\circ}-40^{\circ}$ [25]. In the present study, Fe-Mn-Si-Al steel rolled to $55 \%$ at $673 \mathrm{~K}$ and profuse shear bands inclined at $35^{\circ}$ to the ND plane are observed in most of the grains, as indicated by arrows in Figure $3 \mathrm{~d}_{2}$. These areas with intensely shear bands shown as thick black markings exhibit a very low Confidence Index (CI) value, therefore, no effective orientation information can be detected by EBSD. Hirsch et al. suggested that shear bands are usually formed when the plastic deformation becomes harder to further proceed by dislocation glide [26]. 

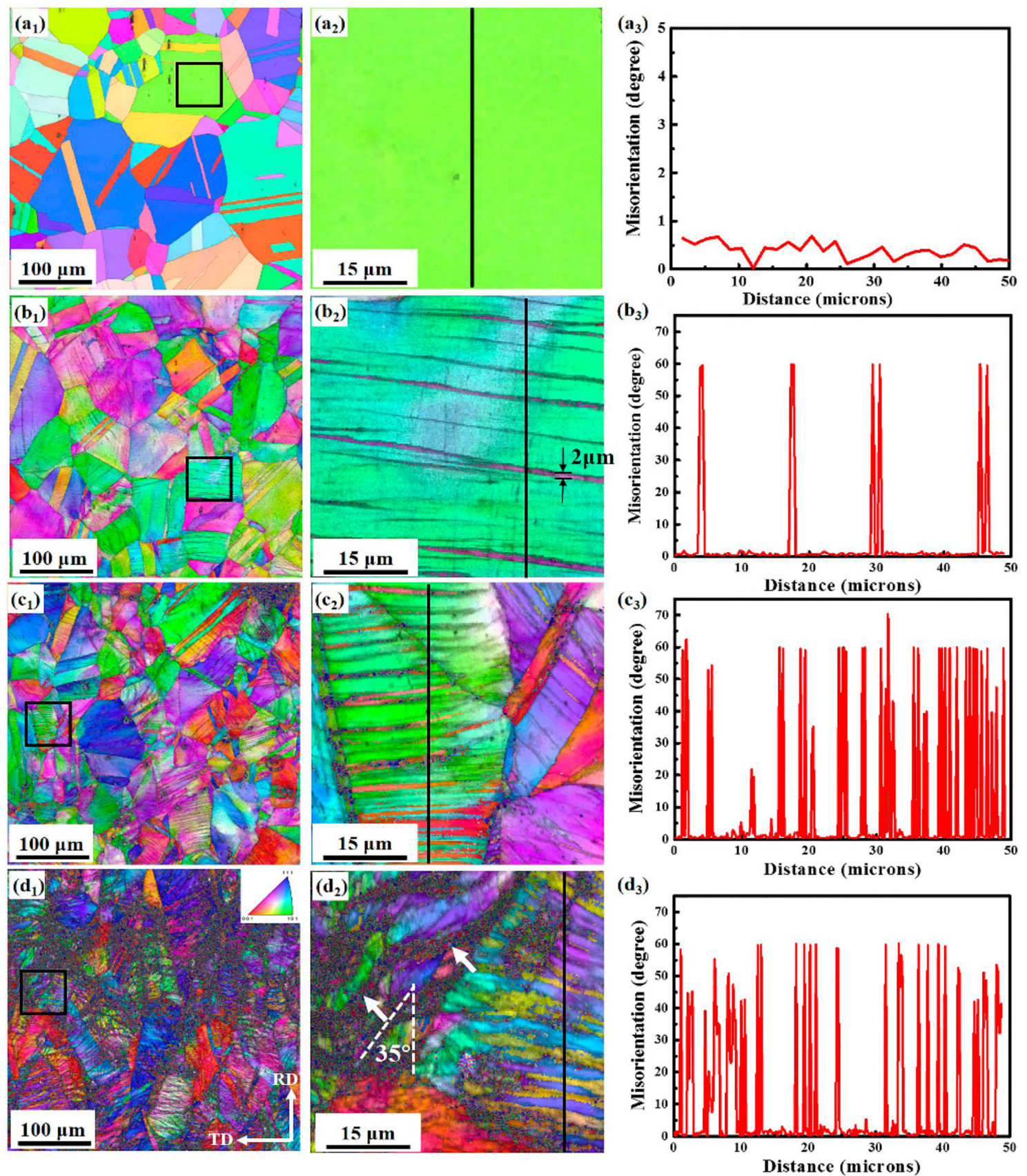

Figure 3. Electron back scattering diffraction (EBSD) maps showing the microstructure of specimens with different warm rolling reductions (a) 20\%, (b) 35\%, (c) 55\%. The inverse pole figure maps of rolling direction (RD) $\left(\mathbf{a}_{\mathbf{1}}, \mathbf{b}_{\mathbf{1}}, \mathbf{c}_{\mathbf{1}}\right)$ and the corresponding enlarged images $\left(\mathbf{a}_{2}, \mathbf{b}_{\mathbf{2}}, \mathbf{c}_{\mathbf{2}}\right)$ taken from the framed area are given. The misorientation profiles $\left(\mathbf{a}_{3}, \mathbf{b}_{3}, \mathbf{c}_{3}\right)$ measured along the lines indicate the existence of intragranular grain boundaries with a misorientation of $60^{\circ}$ (twin boundaries). 


\subsection{Mechanical Properties}

The uniaxial tensile results of the specimens with different rolling reductions are illustrated in Figure 4. A summary of the mechanical properties is also listed in Table 2. The as-annealed specimen exhibits the lowest yield strength $(0.2 \%$ proof stress) of about $258 \mathrm{MPa}$ and the highest total elongation of about $76 \%$. With the increasing rolling reduction, the yield strength is increased and total elongation is reduced. As compared to the as-annealed condition of warm rolled steel with rolling reduction ration of $55 \%$, an obvious improvement in yield strength from $258 \mathrm{MPa}$ to $1036 \mathrm{MPa}$, and a drop in total elongation from $76 \%$ to $20 \%$, is obtained. It should be noted that a yield strength of $785 \mathrm{MPa}$ and a total elongation of $44 \%$ in the case of a warm rolled specimen with rolling reduction of $35 \%$ highlights the potential of pre-strain treatment by warm rolling that could achieve high yield strength-ductility combinations in TRIP/TWIP steels.

Furthermore, three typical groups can be described with respect to the work-hardening behaviors in order to highlight the different deformation stages on the work-hardening rate as a function of true strain curves: Group A (as-annealed), which is characterized by four typical deformation stages; Group B (rolling reduction of $20 \%, 35 \%$ ), in which three typical deformation stages can be identified obviously, and Group C (rolling reduction of 55\%), which is characterized by two typical deformation stages.

Table 2. Mechanical properties for the specimens with different rolling reductions.

\begin{tabular}{cccccc}
\hline $\begin{array}{c}\text { Rolling } \\
\text { Reduction (\%) }\end{array}$ & $\begin{array}{c}\text { Yield Strength } \\
\text { (MPa) }\end{array}$ & $\begin{array}{c}\text { Ultimate } \\
\text { Strength (MPa) }\end{array}$ & $\begin{array}{c}\text { Uniform } \\
\text { Elongation (\%) }\end{array}$ & $\begin{array}{c}\text { Total } \\
\text { Elongation (\%) }\end{array}$ & $\begin{array}{c}\text { Hardness } \\
\text { (HV) }\end{array}$ \\
\hline As-annealed & 258 & 650 & 70 & 76 & 204 \\
20 & 565 & 748 & 47 & 60 & 301 \\
35 & 785 & 834 & 31 & 44 & 368 \\
55 & 1036 & 1049 & 6 & 20 & 425 \\
\hline
\end{tabular}

It is well accepted that four stages can be defined according to the true strain dependency of work-hardening rate $(\mathrm{d} \sigma / \mathrm{d} \varepsilon)$ at the as-annealed condition during the tensile deformation $[17,27]$. The work-hardening rate drops pronouncedly according to the dynamic recovery of dislocations (stage I) $[15,28,29]$. Then, the primary $\varepsilon$-martensite initially nucleates and grows in stage II. At the gradual increase of true strain, the secondary $\varepsilon$-martensite starts to appear and intersect with the primary $\varepsilon$-martensite (stage III). Finally, a significant drop in the work-hardening rate occurs in stage IV, due to the retarded formation of $\varepsilon$-martensite, attributed to the high density of dislocation. The work-hardening rate profiles of the warm rolled specimens with rolling reduction of $55 \%$ exhibit only two stages, namely stage I and IV (Figure $4 \mathrm{~b}$ ). The absence of stage II and III is ascribed to the retarded formation of $\varepsilon$-martensite during tensile deformation at room temperature. Additionally, the corresponding work-hardening rate profiles of the specimens with rolling reductions of $20 \%$ and $35 \%$ show three different stages. It is worth noting that obvious platform can be observed in stage II, which is ascribed to the nucleation and growth of the primary $\varepsilon$-martensite/deformation twin. Meanwhile, the increase of the effective SFE hinders the formation of secondary $\varepsilon$-martensite/deformation twins, therefore, stage III disappears. Grajcar et al. proposed similar strengthening behavior in low C Fe-28Mn-4Si-2Al steel. They suggested that the dominant mechanism responsible for the work-hardening changes as a function of deformation temperature or strain rate, which is related to SFE $[30,31]$. 

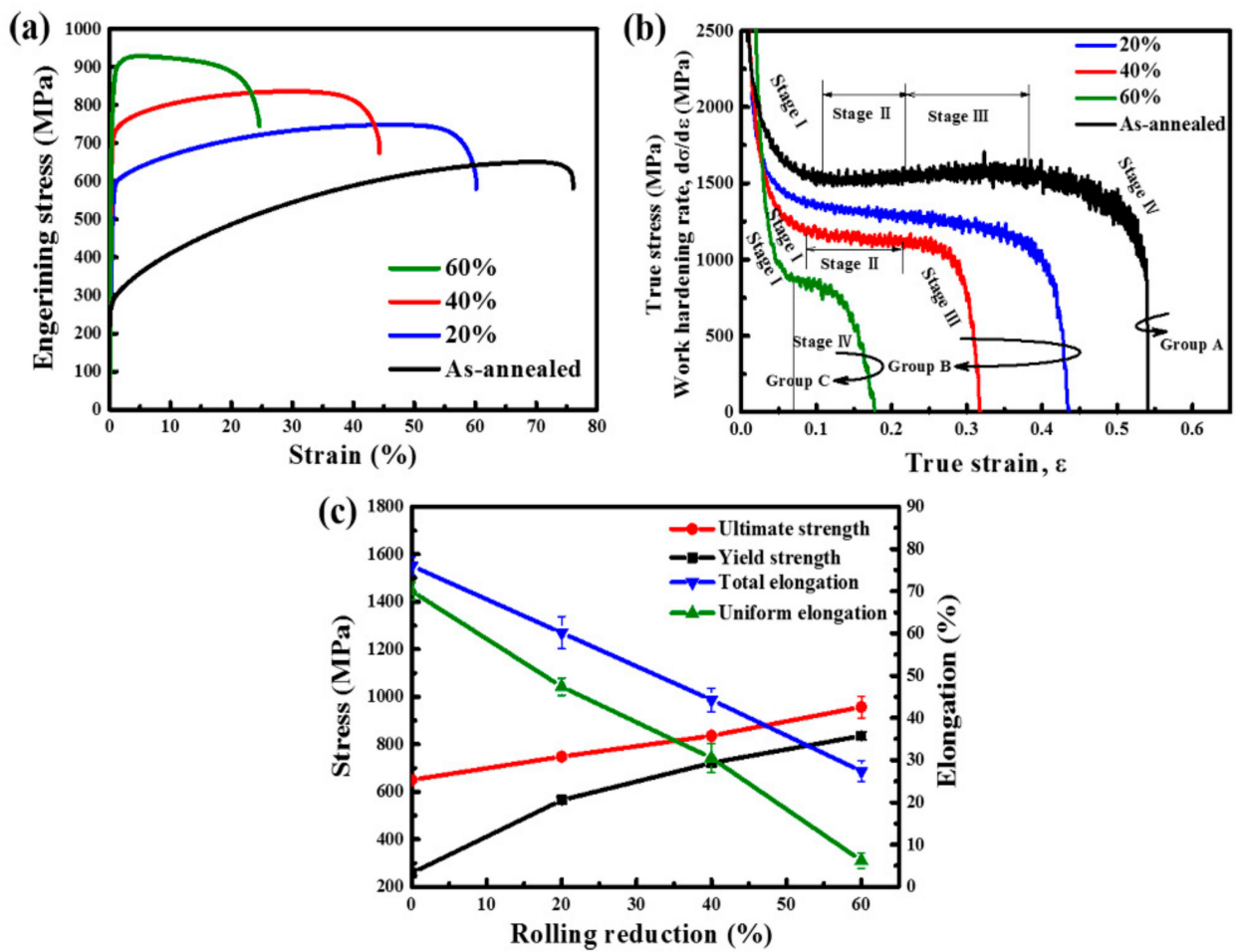

Figure 4. (a) Engineering stress-strain curves; (b) work-hardening rate-true strain curves of the investigated steels with different rolling reductions; (c) plot of mechanical properties vs warm rolling reductions.

\subsection{Fractographic Features}

Characteristic features of the tensile fracture surfaces of the samples with different rolling reductions are presented in Figure 5. The fracture surface of the as-annealed specimen is the typical feature of ductile fracture by the presence of isometric dimples (Figure 5a). Furthermore, there are some flat regions marked with white arrows in Figure $5 d$, indicating failure due to grain boundary sliding in the $55 \%$ condition [32]. The corresponding dimple diameter distribution of samples at different rolling reductions is depicted in Figure 5e. Ductility is strongly related to the number density, depth, size, and distribution of dimples in the fracture surface [33]. It can be seen that different rolling reductions induce various distributions of the mean dimple diameter. In the specimen with rolling reduction of $20 \%$, the mean size of ductile dimples is $3.52 \mu \mathrm{m}$, with a total elongation of $60 \%$. In the specimen with rolling reduction of $25 \%$, the size of ductile dimples is $5.69 \mu \mathrm{m}$, with an elongation of $44 \%$. The size of ductile dimples in the specimen with rolling reduction of $55 \%$ is $8.24 \mu \mathrm{m}$, with an observed elongation of $20 \%$. The mean size of the dimples increases, furthermore, the distribution of dimple dimensions exhibits a fluctuant trend with the increase of the rolling reduction, corresponding to the decrease in total elongation. 

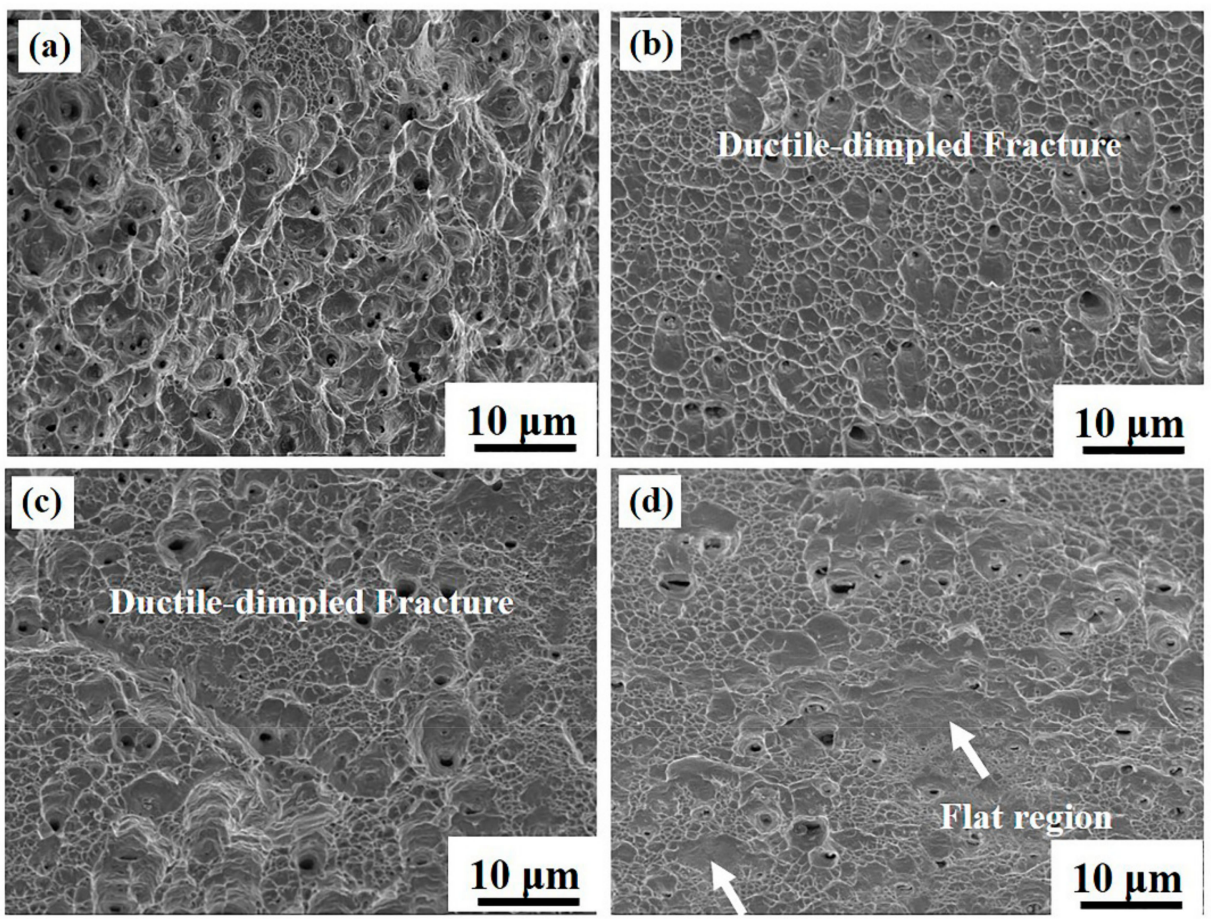

(e)

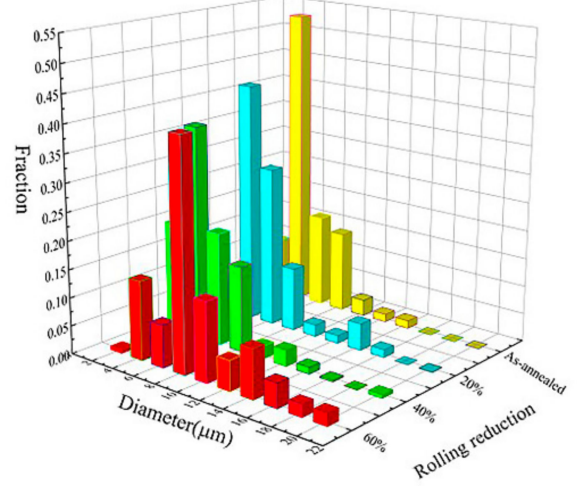

Figure 5. Fracture surfaces of tensile specimens with different rolling reductions: (a) $0 \%$, (b) 20\%, (c) $35 \%$, (d) $55 \%$, (e) rolling reduction dependence of the dimple size.

\subsection{The Effect of Warm Rolling Reduction on Tensile Deformation Behavior}

The XRD profiles for the warm rolled specimens with rolling reduction of $20 \%, 35 \%$, and $55 \%$ after tensile fracture at room temperature are shown in Figure 6. It is interesting to note that the as-formed $\varepsilon$-martensite can be observed in the tensile fractured specimens with rolling reduction of $20 \%$ and $35 \%$. However, no obvious diffraction peaks of $\varepsilon$-martensite can be identified from the XRD pattern with respect to the $55 \%$ rolled specimen after tensile deformation. This is indicative of the absence of deformation-induced $\varepsilon$-martensitic transformation at further tensile deformation condition, which may be ascribed to the derived high dislocation density. 


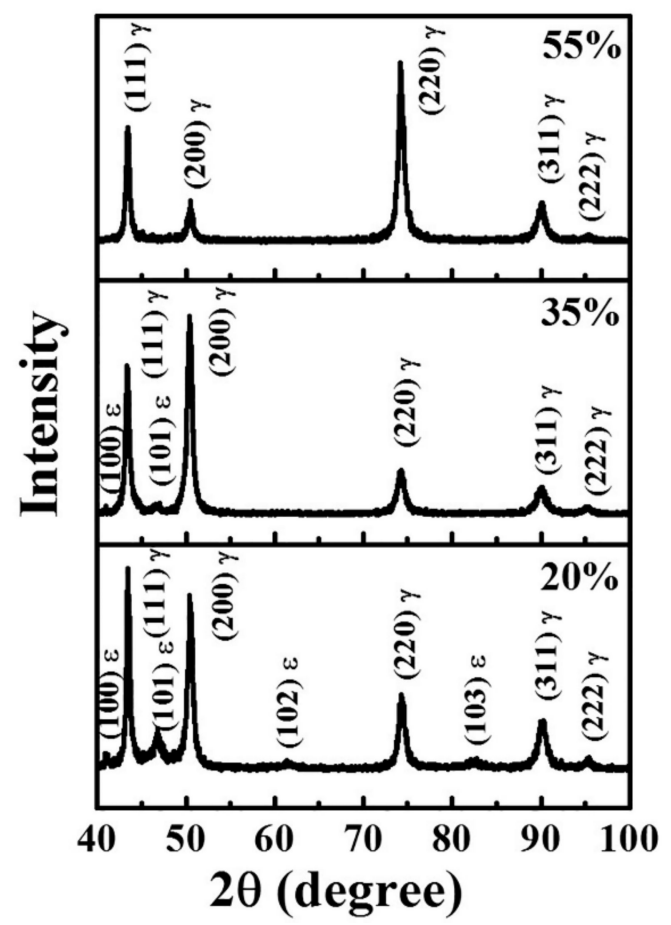

Figure 6. X-ray diffraction patterns of the specimens with different rolling reductions after tensile fracture.

Figure 7 displays the tensile deformation microstructure of the specimen with $35 \%$ rolling reduction. The RD orientation map and phase map are given in Figure 7a,b, respectively. With the OIM analytical software, the area fraction of $\varepsilon$-martensite is estimated to be $21 \%$. As observed in those maps, there are two grains (Grain 1 and Grain 2) which contain clear $\varepsilon$-martensite with banded structures. Furthermore, deformation twins with various thicknesses ranging from $5-50 \mu \mathrm{m}$, as shown by arrows, are observed. The thickness of the twin indicates that some of those deformation twins are formed during tensile deformation. For analyzing the microstructure after tensile deformation in more detail, a small region taken from the framed area in Grain 1 is observed in a fine step size, as show in Figure 8.

Figure $8 \mathrm{~b}$ shows the RD orientation map for $\gamma$ phase where the $\gamma$ phases are colored depending on their orientation and $\varepsilon$ phases are blacked out. In contrast, the colored and blacked out regions are inverted in $\varepsilon$ orientation map (Figure 8c). The microstructure consists of $\gamma$ matrix in purple, deformation twins in red, and some deformation induced $\varepsilon$-martensite in yellow (Figure $8 \mathrm{a}$ ). The orientation of the $\gamma$ matrix is determined at a scanning spot as ND//(20 $4-13), \mathrm{RD} / /(-2-3-4)$. It is observed that $\varepsilon$-martensite and the deformation twins with plate-like morphology are parallel to each other. Therefore, the primary $(1-1-1)_{\text {matrix }}$ plane is defined as the habit plane of $\varepsilon$ variant and twinning plane of deformation twin, as shown in Figure 8e,f. With respect to the Schmid law, the most plausible shear direction is [ $-2-1-1]$, with a Schmid factor of 0.477 . The analogous results can also be observed in Grain 2. The matrix with blue color with the crystal orientation of the miller indices $\mathrm{ND} / /(-3-157), \mathrm{RD} / /(3-2-3)$, is shown in Figure 9 a. The parallel $\varepsilon$ martensite and deformation twin are induced by the most plausible shear direction as [1 -2 -1] on the primary $(-1-11)_{\text {matrix }}$ plane with a Schmid factor of 0.429 . It should be noted that $\varepsilon$ martensite and deformation twins are closely next to each other both in Grain 1 and Grain 2 . Therefore, it can be speculated that $\varepsilon$ martensitic transformation and twinning simultaneously operate during tensile deformation in the specimen with a rolling reduction of $35 \%$. 

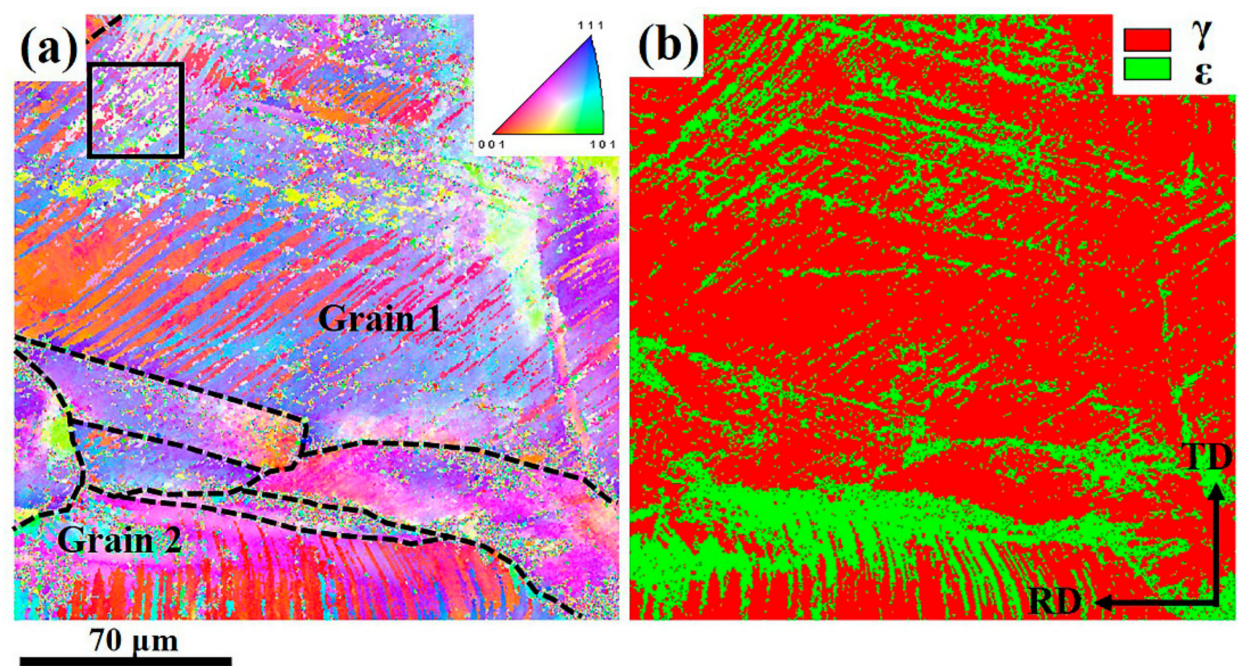

Figure 7. Microstructure of tensile deformed specimen with warm rolling reduction of 35\%: (a) The RD orientation maps, (b) phase map.

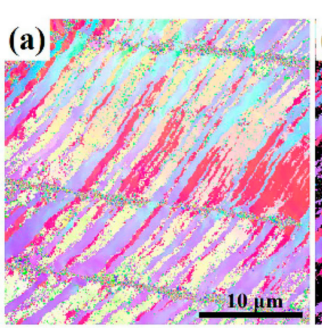

(e) $\{111\}$

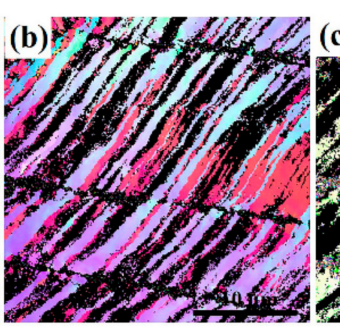

(f) $\{0001\}$

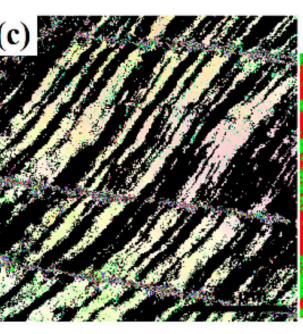

TD

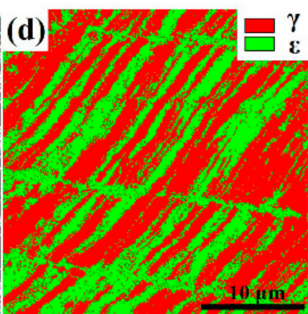

Iron (Ensilion)

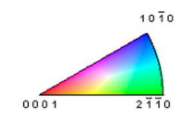

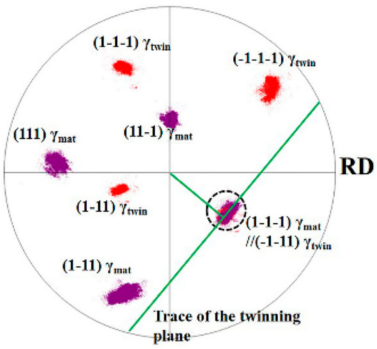

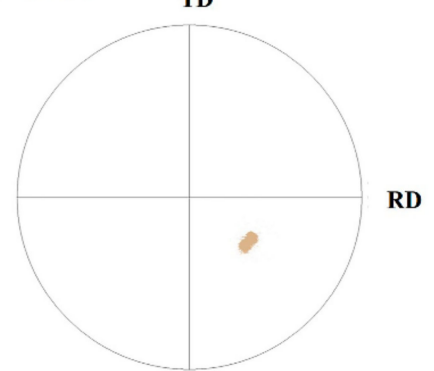

RD

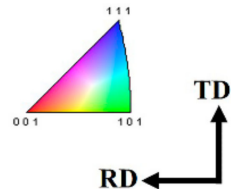

Figure 8. Microstructure of tensile deformed specimen after $35 \%$ warm rolling reduction, taking at the framed area in Grain 1: (a) The RD orientation maps for all data, (b) the FCC structures, (c) HCP structures, (d) phase map, (e) $\{111\}$ pole figure and (f) $\{0001\}$ pole figure. 

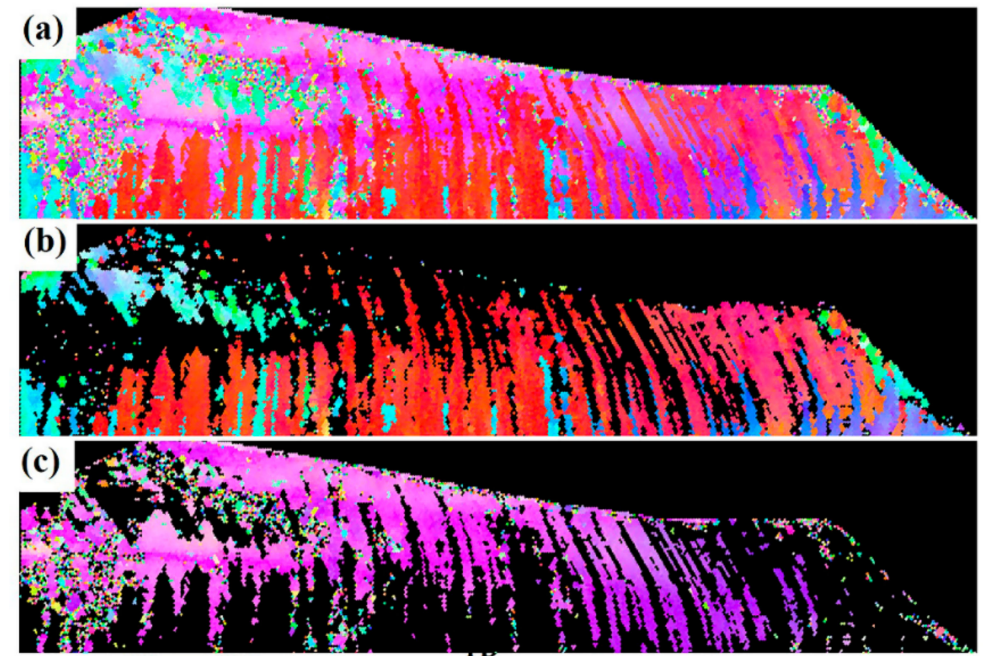

(d)

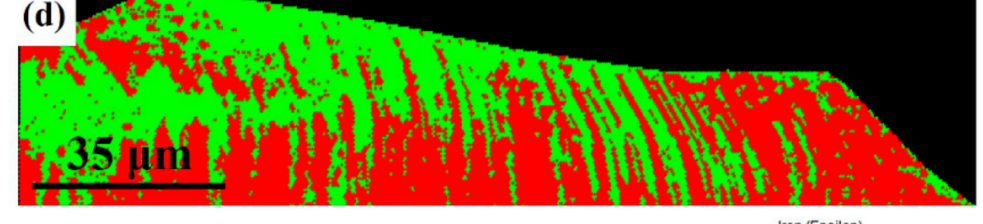

(e) $\{111\}$

(f) $\{0001\}$

Iron (Epsilon)
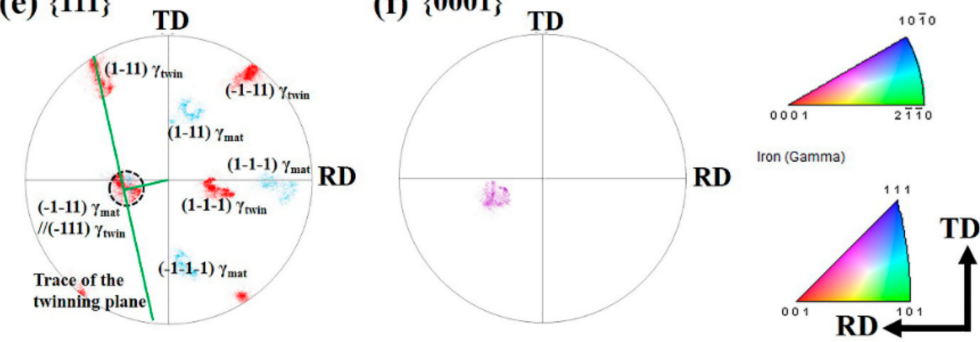

Figure 9. Microstructure of tensile deformed specimen after $35 \%$ warm rolling reduction, taking at Grain 2: (a) The RD orientation maps for all data, (b) the FCC structures, (c) HCP structures, (d) phase map, (e) $\{111\}$ pole figure and (f) $\{0001\}$ pole figure.

It is well known that the mechanisms of formation of $\varepsilon$ martensite and twins are similar [34]. Both $\varepsilon$ and twins are formed by the movement of Shockley partial dislocations and subsequent intrusion of stacking faults, on every other $\{111\}$ close-packed plane for the former and on every $\{111\}$ plane for the latter. In Mahajan's model, an ensemble of three Shockley partials on every second $\{111\}$ plane are induced by two perfect dislocation reactions, which may govern the nucleation of six-layer HCP crystal. A macroscopic $\varepsilon$-martensite forms when these three Shockley partials on every second $\{111\}$ plane grow into each other. These situations imply the stacking faults are required for $\varepsilon$-martensite nucleation. Furthermore, Inagaki et al. illustrated the reverse transformation of the $\varepsilon$-martensite by in-situ TEM observations [35]. They supported that the Shockley partial dislocations "at one end" moved towards the other "immobile end", fixed at grain boundaries or interfaces of pre-existing $\varepsilon$ plates. Therefore, all of the followings can be the possible nucleation sites of the $\varepsilon$-martensite: dislocations, grain boundaries, and pre-existing plates (or stacking faults). This is in accordance with our results that $\varepsilon$-martensite always emerges along the deformation twin boundaries.

A schematic sketch of microstructure evolution during the warm rolling process and subsequent tensile deformation, exhibiting the mechanism of pre-strain twinning and $\varepsilon$-martensite transformation asynchronous deformation, is provided in Figure 10. In the as-annealed state, the microstructure consists of FCC $\gamma$ matrix and quite a few dislocations (Figure 10a). The prior warm rolling results in the evolution of sub-structure, comprising dislocations, deformation twins and shear bands, depending on the warm rolling reduction (Figure 10b-d). It can be concluded that the deformation-induced $\varepsilon$-martensitic transformation is the single deformation mechanism that dominates plasticity, besides 
the dislocation glide, in a specimen without prior warm rolling (Figure 10e). However, $\varepsilon$-martensite and deformation twins form simultaneously when the prior warm rolling reduction reaches $35 \%$ (Figure 10f). Then, with further increasing warm rolling reduction to $55 \%$, the deformation mechanism transits to dislocation glide (Figure 10g). The occurrence of this transition of deformation mechanism depends on effective SFE. It is well accepted that the $\varepsilon$-martensite occurs if the SFE is typically below $20 \mathrm{~mJ} \cdot \mathrm{m}^{-2}$, whereas deformation twins form when the SFE lies between 15 and $30 \mathrm{~mJ} \cdot \mathrm{m}^{-2}$ [8]. A higher SFE favors dislocation glide. Hence, $\varepsilon$-martensitic transformation and twinning occur simultaneously if the SFE is between 15 and $20 \mathrm{~mJ} \cdot \mathrm{m}^{-2}$. Meanwhile, an increasing dislocation density with the increasing warm rolling reduction is expected to enhance effective SFE. Therefore, the warm rolling reduction has a strong effect on the transition of the tensile deformation mechanism.

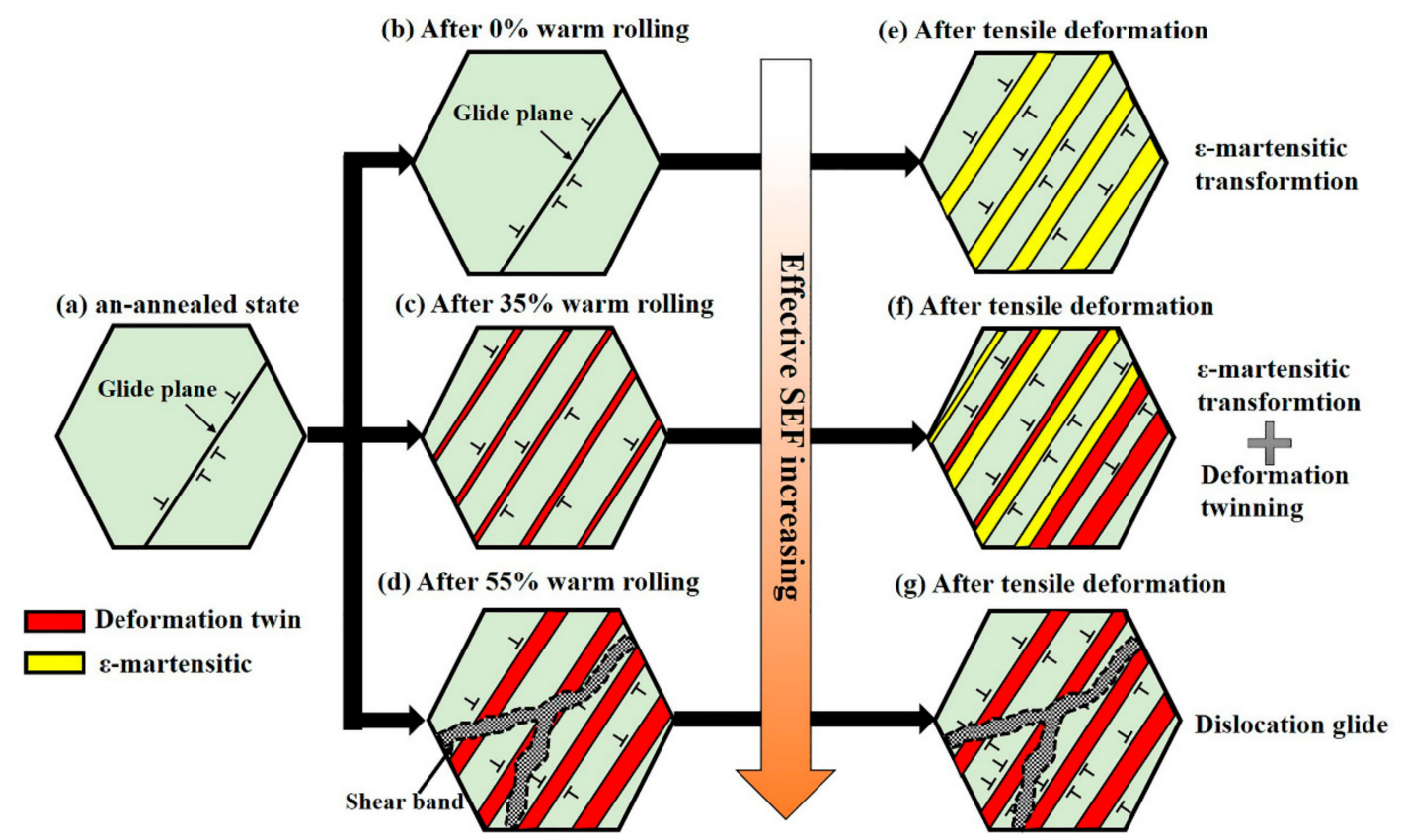

Figure 10. A schematic sketch of microstructure evolution during warm rolling and tensile deformation (green, red and yellow colors denote austenite matrix, deformation twin and $\varepsilon$-martensite, respectively).

Figure 11 shows the resultant yield stress-ductility combination of Fe-30Mn-4Si-2Al TRIP/TWIP steel by prior warm rolling, together with the data from references $[10,15,16,29,36-41]$. First, previous reporting attempted to refine grain size to improve the yield stress by the conventional cold rolling and annealing treatment. This offer high ductility, but low yield stress $(<500 \mathrm{MPa})$, as indicated by the blue dashed lines. Secondly, the precipitation strengthening strategy is one of the more efficient ways to increase yield stress. However, some precipitations formed at grain boundaries are harmful to toughness and ductility. Furthermore, the improvement of yield stress is limited by the addition of microalloy elements, as shown by the green dashed line. The third point to note in Figure 11 is that, comparing our results (red dashed line) with those by cold rolling (yellow dashed line), ductility is increased at any given yield stress. Therefore, this advantage of the present warm rolling strategy is especially pronounced at high yield strength toward $800 \mathrm{MPa}$ and good ductility. 


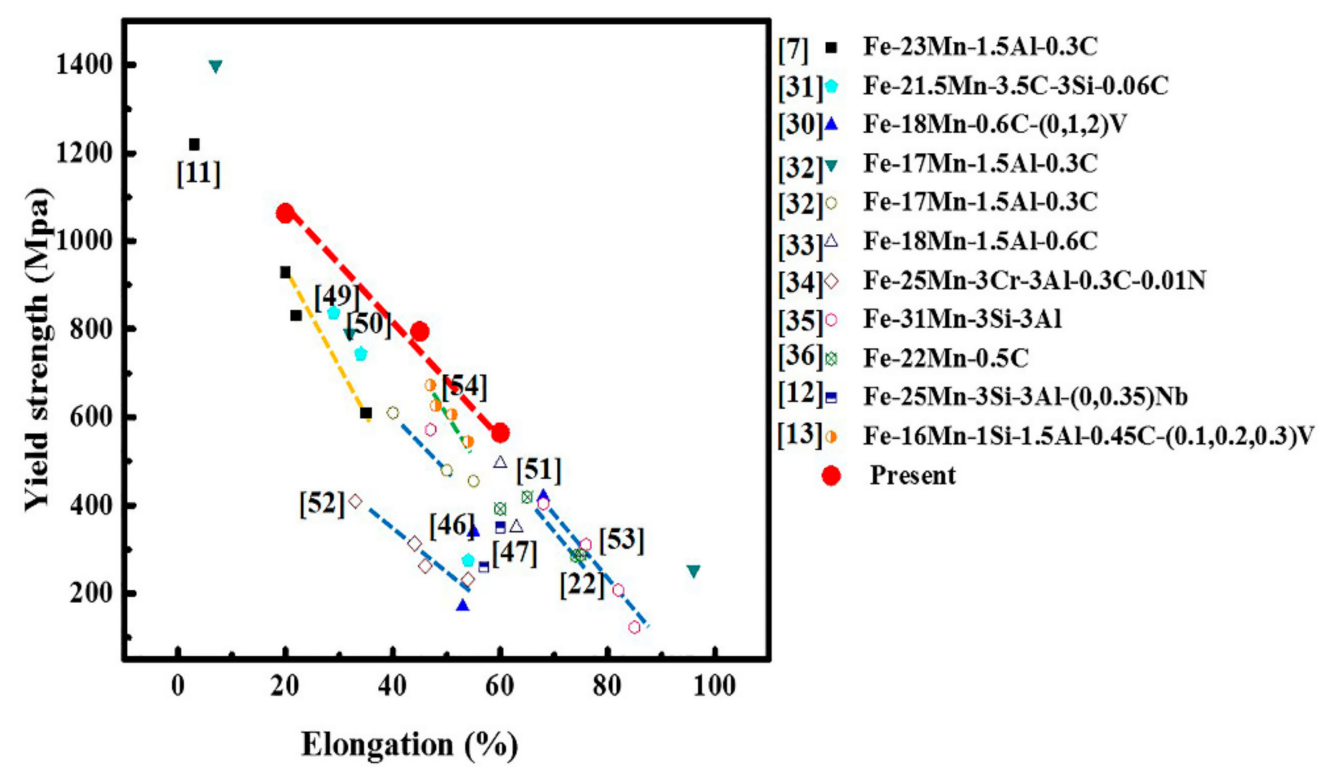

Figure 11. Comparison between the present TRIP/TWIP steel and previous results.

\section{Conclusions}

We have focused on the effect of prior warm rolling reduction on tensile deformation behavior and corresponding mechanical properties of an Fe-30Mn-4Si-2Al TRIP/TWIP steel. The mechanisms of pre-strain twinning and $\varepsilon$-martensite transformation asynchronous deformation were studied. The influence of rolling reduction on the work-hardening behavior was discussed. The main conclusions are as follows:

(1) The microstructure of the steel after $20 \%$ warm rolling was characterized by low dislocation density and thin deformation twins within the initial grains. The density of dislocation and deformation twins are raised at the increase of rolling reduction. After a 55\% rolling reduction, shear bands appeared, as the plastic deformation becomes harder to further proceed by dislocation glide.

(2) After tensile deformation, the growth of deformation twins are observed, and the primary $\varepsilon$ is always found to be parallel and close to a deformation twin, indicating that the possible nucleation sites of the $\varepsilon$-martensite may be the pre-existing twin boundaries, in the specimen with warm a rolling reduction of $35 \%$.

(3) The experimental steel with a warm rolling reduction of 35\% exhibits a superior combination of high yield strength and ductility (yield strength of $785 \mathrm{MPa}$ and total elongation of $44 \%$ ) as well as a high work hardening rate due to the coexistence of deformation twins and $\varepsilon$-martensite.

(4) A deformation mechanism was proposed that started from a single $\varepsilon$-martensitic transformation to a bi-mode of $\varepsilon$-martensitic transformation and was accompanied by deformation twinning, before finally moving to dislocation glide with the increase in warm rolling reduction.

Author Contributions: F.Y., Y.D. and J.F. conceived and designed the experiments; Z.S., H.X. and J.D. performed the experiments; X.Z., G.W. and L.L. wrote the paper. B.L. and W.F. directed the research and contributed to the discussion and interpretation of the results.

Acknowledgments: The research gratefully acknowledge the financial support from the National Natural Science Foundation of China (No. 51705129); the Natural Science Foundation of Hebei Province (No. E2016202121) and Hebei Province Education Department Science and Technology Research Project (No. BJ2017009); Foundation for High-level Talents in Higher Education of Hebei, China (No. GCC2014012); State Key Lab of Advanced Metals and Materials (No. 2017-Z02).

Conflicts of Interest: The authors declare no conflict of interest. 


\section{References}

1. Yuan, X.; Zhao, Y.; Li, X.; Chen, L. Au nanoparticles decorated graphene/nickel foam nanocomposite for sensitive detection of hydrogen peroxide. J. Mater. Sci. Technol. 2017, 33, 1555-1560. [CrossRef]

2. De Cooman, B.C.; Estrin, Y.; Kim, S.K. Twinning-induced plasticity (TWIP) steels. Acta Mater. 2018, 142, 283-362. [CrossRef]

3. Ofei, K.A.; Zhao, L.; Sietsma, J. Microstructural Development and Deformation Mechanisms during Cold Rolling of a Medium Stacking Fault Energy TWIP Steel. J. Mater. Sci. Technol. 2013, 29, 161-167. [CrossRef]

4. Torganchuk, V.I.; Belyakov, A.; Kaibyshev, R. Effect of rolling temperature on microstructure and mechanical properties of 18\% Mn TWIP/TRIP steels. Mater. Sci. Eng. A 2017, 708, 110-117. [CrossRef]

5. Torganchuk, V.; Glezer, A.M.; Belyakov, A.; Kaibyshev, R. Deformation behavior of high-Mn TWIP steels processed by warm-to-hot working. Metals 2018, 8, 415. [CrossRef]

6. Imandoust, A.; Zarei-Hanzaki, A.; Sabet, M.; Abedi, H.R. An analysis of the deformation characteristics of dual phase twinning-induced plasticity steel in warm temperature regime. Mater. Des. 2012, 40, 556-561. [CrossRef]

7. Curtze, S.; Kuokkala, V.T.; Oikari, A.; Talonen, J.; Hänninen, H. Thermodynamic modeling of the stacking fault energy of austenitic steels. Acta Mater. 2011, 59, 1068-1076. [CrossRef]

8. Allain, S.; Chateau, J.P.; Bouaziz, O.; Migot, S.; Guelton, N. Correlations between the calculated stacking fault energy and the plasticity mechanisms in Fe-Mn-C. alloys. Mater. Sci. Eng. A 2004, 387-389, 158-162. [CrossRef]

9. Bouaziz, O.; Allain, S.; Scott, C.P.; Cugy, P.; Barbier, D. Twinning-induced plasticity (TWIP) steels. Solid State Mater. Sci. 2011, 15, 141-168. [CrossRef]

10. Haase, C.; Barrales-Mora, L.A.; Roters, F.; Molodov, D.A.; Gottstein, G. Applying the texture analysis for optimizing thermomechanical treatment of high manganese twinning-induced plasticity steel. Acta Mater. 2014, 80, 327-340. [CrossRef]

11. Kim, J.G.; Enikeev, N.A.; Abramova, M.M.; Park, B.H.; Valiev, R.Z.; Kim, H.S. Effect of initial grain size on the microstructure and mechanical properties of high-pressure torsion processed twinning-induced plasticity steels. Mater. Sci. Eng. A 2017, 682, 164-167. [CrossRef]

12. Liu, S.; Qian, L.; Meng, J.; Li, D.; Ma, P.; Zhang, F. Simultaneously increasing both strength and ductility of Fe-Mn-C twinning-induced plasticity steel via Cr/Mo alloying. Scr. Mater. 2017, 127, 10-14. [CrossRef]

13. Rahman, K.M.; Vorontsov, V.A.; Dye, D. The effect of grain size on the twin initiation stress in a TWIP steel. Acta Mater. 2015, 89, 247-257. [CrossRef]

14. Haase, C.; Kremer, O.; Hu, W.; Ingendahl, T.; Lapovok, R.; Molodov, D.A. Equal-channel angular pressing and annealing of a twinning-induced plasticity steel: Microstructure, texture, and mechanical properties. Acta Mater. 2016, 107, 239-253. [CrossRef]

15. Li, D.; Feng, Y.; Song, S.; Liu, Q. Influences of Nb-microalloying on microstructure and mechanical properties of Fe-25Mn-3Si-3Al TWIP steel. Mater. Des. 2015, 84, 238-244. [CrossRef]

16. Gwon, H.; Kim, J.K.; Shin, S.; Cho, L.; Cooman, B.C.D. The effect of vanadium micro-alloying on the microstructure and the tensile behavior of TWIP steel. Mater. Sci. Eng. A 2017, 696, 416-428. [CrossRef]

17. Yin, F.X.; Xia, H.; Feng, J.H.; Cai, M.H.; Zhang, X.; Wang, G.K.; Sawaguchi, T. Mechanical properties of an Fe-30Mn-4Si-2Al alloy after rolling at different temperatures ranging from 298 to $1073 \mathrm{~K}$. Mater. Sci. Eng. A 2018, 725, 127-137. [CrossRef]

18. Zhang, X.; Sawaguchi, T.; Ogawa, K.; Yin, F.; Zhao, X. A structure created by intersecting e martensite variant plates in a high-manganese steel. Philos. Mag. 2011, 91, 4410-4426. [CrossRef]

19. Kimura, Y.; Inoue, T.; Yin, F.; Tsuzaki, K. Inverse temperature dependence of toughness in an ultrafine grain-structure steel. Science 2008, 320, 1057-1060. [CrossRef] [PubMed]

20. Curtze, S.; Kuokkala, V.T. Dependence of tensile deformation behavior of TWIP steels on stacking fault energy, temperature and strain rate. Acta Mater. 2010, 58, 5129-5141. [CrossRef]

21. Taylor, F.R.S.G.I. The mechanism of plastic deformation of crystals. Part I.-Theoretical. Proc. R. Soc. Lond. A 1934, 145, 388-404. [CrossRef]

22. He, B.B.; Hu, B.; Yen, H.W.; Cheng, G.J.; Wang, Z.K.; Luo, H.W.; Huang, M.X. High dislocation density-induced large ductility in deformed and partitioned steels. Science 2017, 357, 1029. [CrossRef] [PubMed] 
23. Mahato, B.; Shee, S.K.; Sahu, T.; Ghosh Chowdhury, S.; Sahu, P.; Porter, D.A.; Karjalainen, L.P. An effective stacking fault energy viewpoint on the formation of extended defects and their contribution to strain hardening in a Fe-Mn-Si-Al twinning-induced plasticity steel. Acta Mater. 2015, 86, 69-79. [CrossRef]

24. Pierce, D.T.; Jiménez, J.A.; Bentley, J.; Raabe, D.; Oskay, C.; Wittig, J.E. The influence of manganese content on the stacking fault and austenite/ $\varepsilon$-martensite interfacial energies in Fe-Mn-(Al-Si) steels investigated by experiment and theory. Acta Mater. 2014, 68, 238-253. [CrossRef]

25. Kawahara, K. A possibility for developing high strength soft magnetic materials in FeCo-X alloys. J. Mater. Sci. 1984, 19, 949-956. [CrossRef]

26. Hirsch, J.; Lücke, K.; Hatherly, M. Overview No. 76: Mechanism of deformation and development of rolling textures in polycrystalline fcc Metals-III. The inflence of slip inhomogeneities and twinning. Acta Metall. 1988, 36, 2905-2927. [CrossRef]

27. Barbier, D.; Gey, N.; Allain, S.; Bozzolo, N.; Humbert, M. Analysis of the tensile behavior of a TWIP steel based on the texture and microstructure evolutions. Mater. Sci. Eng. A 2009, 500, 196-206. [CrossRef]

28. Jin, J.E.; Lee, Y.K. Strain hardening behavior of a Fe-18Mn-0.6C-1.5Al TWIP steel. Mater. Sci. Eng. A 2009, 527, 157-161. [CrossRef]

29. Jin, J.E.; Lee, Y.K. Effects of $\mathrm{Al}$ on microstructure and tensile properties of C-bearing high Mn TWIP steel. Acta Mater. 2012, 60, 1680-1688. [CrossRef]

30. Grajcar, A.; Kozłowska, A.; Topolska, S.; Morawiec, M. Effect of deformation temperature on microstructure evolution and mechanical properties of low-carbon high-Mn steel. Adv. Mater. Sci. Eng. 2018, 2018, 1-7. [CrossRef]

31. Grajcar, A.; Kozłowska, A.; Grzegorczyk, B. Strain hardening behavior and microstructure evolution of high-manganese steel subjected to interrupted tensile test. Metals 2018, 8, 122. [CrossRef]

32. Carpenter, K.R.; Dippenaar, R.; Killmore, C.R. Hot Ductility of Nb- and Ti-Bearing Microalloyed Steels and the Influence of Thermal History. Metall. Mater. Trans. A 2009, 40, 573-580. [CrossRef]

33. Neeraj, T.; Srinivasan, R.; Li, J. Hydrogen embrittlement of ferritic steels: Observations on deformation microstructure, nanoscale dimples and failure by nanovoiding. Acta Mater. 2012, 60, 5160-5171. [CrossRef]

34. Idrissi, H.; Renard, K.; Ryelandt, L.; Schryvers, D.; Jacques, P.J. On the mechanism of twin formation in Fe-Mn-C TWIP steels. Acta Mater. 2010, 58, 2464-2476. [CrossRef]

35. Inagaki, $\mathrm{H}$. In situ TEM observations of the $\varepsilon \rightarrow \gamma$ reverse transformation in an $\mathrm{Fe}-14 \% \mathrm{Mn}-6 \% \mathrm{Si}-9 \% \mathrm{Cr}-6 \%$ Ni shape memory alloy. Z. Metallkunde 1992, 84, 304-309.

36. Tewary, N.K.; Ghosh, S.K.; Bera, S.; Chakrabarti, D.; Chatterjee, S. Influence of cold rolling on microstructure, texture and mechanical properties of low carbon high Mn TWIP steel. Mater. Sci. Eng. A 2014, 615, 405-415. [CrossRef]

37. Yanushkevich, Z.; Belyakov, A.; Kaibyshev, R.; Haase, C.; Molodov, D.A. Effect of cold rolling on recrystallization and tensile behavior of a high-Mn steel. Mater. Charact. 2016, 112, 180-187. [CrossRef]

38. Kang, S.; Jung, J.G.; Kang, M.; Woo, W.; Lee, Y.K. The effects of grain size on yielding, strain hardening, and mechanical twinning in Fe-18Mn-0.6C-1.5Al twinning-induced plasticity steel. Mater. Sci. Eng. A 2016, 652, 212-220. [CrossRef]

39. Yuan, X.; Chen, L.; Zhao, Y.; Di, H.; Zhu, F. Influence of annealing temperature on mechanical properties and microstructure of a high manganese austenitic steel. J. Mater. Process. Technol. 2015, 217, 278-285. [CrossRef]

40. Dini, G.; Najafizadeh, A.; Ueji, R.; Monir-Vaghefi, S.M. Tensile deformation behavior of high manganese austenitic steel:The role of grain size. Mater. Des. 2010, 31, 3395-3402. [CrossRef]

41. Lan, P.; Zhang, J. Tensile property and microstructure of Fe-22Mn-0.5C TWIP steel. Mater. Sci. Eng. A 2017, 707, 373-382. [CrossRef]

(C) 2018 by the authors. Licensee MDPI, Basel, Switzerland. This article is an open access article distributed under the terms and conditions of the Creative Commons Attribution (CC BY) license (http:/ / creativecommons.org/licenses/by/4.0/). 